\title{
Monitoring of alien mosquitoes of the genus Aedes (Diptera: Culicidae) in Austria
}

\author{
Ellen Schoener ${ }^{1} \cdot$ Carina Zittra $^{1} \cdot$ Stefan Weiss $^{2} \cdot$ Gernot Walder $^{3,4} \cdot$ Bita Shahi Barogh $^{1} \cdot$ Stefanie Weiler $^{4}$. \\ Hans-Peter Fuehrer ${ }^{1}$ (D)
}

Received: 31 August 2018 / Accepted: 6 March 2019 / Published online: 16 March 2019

(C) The Author(s) 2019

\begin{abstract}
Systematic, continuous mosquito surveillance is considered the most reliable tool to predict the spread and establishment of alien mosquito species such as the Asian tiger mosquito (Aedes albopictus), Japanese bush mosquito (Aedes japonicus), and the transmission risk of mosquito-borne arboviruses to humans. Only single individuals of Ae. albopictus have been found in Austria so far. However, it is likely that the species will be able to establish populations in the future due to global trade and traffic as well as increasing temperatures in the course of global climate change. In summer 2017, a project surveilling the oviposition of newly introduced Aedes mosquitoes, using ovitraps, was set up by means of citizen scientists and researchers and was performed in six federal provinces of Austria - Tyrol, Carinthia, Vienna, Lower Austria, Styria, and Burgenland. Eggs of Ae. albopictus were identified in Tyrol during the months August and September, while Ae. japonicus was found in Lower Austria, Styria, and Burgenland. In Vienna and Carinthia, all ovitraps were negative for Aedes eggs; however, Ae. japonicus was found for the first time in Vienna in July 2017 during routine sampling of adult mosquitoes. With this project, we demonstrated the benefits of citizen scientists for ovitrap-based mosquito surveillance. The finding of Ae. albopictus eggs in Northern Tyrol is not yet a proof of the establishment of a self-sustaining population, although it indicates the ongoing introduction of this species along main traffic routes from Italy, where this mosquito is well established. The risk of establishment of the tiger mosquito in the Lower Inn Valley is therefore a given and informing the public about preventive measures to hinder and delay this development is highly recommended.
\end{abstract}

Keywords Alien mosquitoes $\cdot$ Aedes albopictus $\cdot$ Aedes japonicus $\cdot$ Monitoring $\cdot$ Ovitraps

\section{Introduction}

Fourty-nine mosquito species (Diptera: Culicidae) belonging to eight genera (Aedes, Anopheles, Culex, Coquillettidia, Culiseta, Ochlerotatus, Orthopodomyia, and Uranotaenia) have been specified in Austria so far (cf. Zittra et al. 2017a).

Handling Editor: Julia Walochnik

Hans-Peter Fuehrer

Hans-Peter.Fuehrer@vetmeduni.ac.at

1 Institute of Parasitology, Department of Pathobiology, University of Veterinary Medicine Vienna, Veterinaerplatz 1, 1210 Vienna, Austria

2 Burgauberg-Neudauberg, Austria

3 Division of Hygiene and Medical Microbiology, Medical University of Innsbruck, Innsbruck, Austria

4 Dr. Gernot Walder GmbH, Außervillgraten, Austria
The establishment of the potential invasive species Aedes (Stegomyia) albopictus (Skuse, 1984) (Asian tiger mosquito) and Aedes (Hulecoeteomyia) japonicus (Theobald, 1901) (Asian rock pool or Asian bush mosquito) in Austria has been in dispute until recently (Seidel et al. 2012; Zittra et al. 2015). Moreover, three additional non-native species, Anopheles (Anopheles) hyrcanus (Pallas, 1771), Orthopodomyia pulcripalpis (Rondani, 1872), and Culiseta (Allotheobaldia) longiareolata (Macquart, 1838), have been reported in recent years (Lebl et al. 2013; Seidel et al. 2013a, b; Zittra et al. 2017b, 2015, 2014).

The following three alien mosquitoes are expanding their range in Europe: Aedes albopictus, Aedes (Hulecoeteomyia) koreicus (Edwards, 1917), and Aedes japonicus. These species originate from Asia and have increased their range in Europe over the past decade (Medlock et al. 2012; Walder et al. 2013; Medlock et al. 2015; Cunze et al. 2016a, b). Aedes japonicus originates from a temperate climate zone 
and while its range is likely to expand into Northern and temperate regions of Europe, it is not able to adapt to warmer climates (Cunze et al. 2016a, b), whereas Ae. albopictus is currently restricted to Southern Europe but is expected to expand its range as climate change continues to occur (Cunze et al. 2016a, b). This is of importance, because the Asian tiger mosquito Ae. albopictus is known for its high ecological and climatic adaptability and is now found as an invasive species on all continents except Antarctica (Bonizzoni et al. 2013). It is adaptable enough to adjust to more temperate climates (Goubert et al. 2017) and since its introduction into Germany, it has already been able to reproduce in high numbers at certain sites in 2015 (Becker et al. 2017). The Asian tiger mosquito is of public health concern since it is a vector of different arboviruses (Paupy et al. 2009; Schaffner et al. 2013) like dengue (Rezza 2012, Ferreira-de-Lima, and LimaCamara 2018) and Chikungunya virus (Poletti et al. 2011; Carrieri et al. 2012). While Ae. japonicus appears to be of lesser public health importance, it is a potential vector for West Nile virus at least in laboratory experiments (Wagner et al. 2018). In Austria, Ae. japonicus was firstly observed in 2011 in Styria near the Slovenian border in an artificial water container (Seidel et al. 2012). Between 2010 and 2015, it is assumed that the species expanded eastwards into Burgenland and westwards into Carinthia (Seidel et al. 2016a, b). Since then, the Carinthian population has possibly spread southwards to Northern Italy. Between 2014 and 2016, findings of Ae. japonicus females in Burgenland and Lower Austria (Zittra et al. 2017a) highlight the expanding distribution of this alien species in Austria. Moreover, Ae. japonicus was also found in 2015 in Vorarlberg (Western Austria) possibly originating from established populations in Switzerland (Seidel et al. 2016a, b). In contrast, Ae. albopictus was not widely distributed as Ae. japonicus. Contrarily, Aedes albopictus was found once in Austria in Jennersdorf, Burgenland, in its immature stages and as a single female (Seidel et al. 2012) and seemed to be restricted to finding single individuals and clutches in the Inntal valley along transit routes until now as demonstrated by a continuous monitoring of this area using so-called "ovitraps" (Walder 2017).

Ovitraps, which operate by attracting female mosquitoes, have been frequently used in Southern Europe for the surveillance of invasive mosquito species (Carrieri et al. 2012; Velo et al. 2016; Baldacchino et al. 2017; Di Luca et al. 2017; Manica et al. 2017) and are also recommended by the ECDC (European Centre for Disease Prevention and Control 2012). Citizen scientists, interested members of the public participating in scientific studies, have also recently been included for mosquito surveillance in both Germany (Walter and Kampen 2017), Spain (Palmer et al. 2017), and the USA (Jordan et al. 2017). These studies, however, relied on the report of adult female invasive mosquitoes by more or less trained members of the public, while in our own study, we provided ovitraps to all participating volunteers. The use of citizen scientists provides advantages such as increased reach of the study area as well as saving money and time.

In the summer 2017, a surveillance project using ovitraps, which were set up in five federal states of Austria, was performed, to predict and determine the presence and distribution of the alien mosquito species Ae. albopictus, Ae. koreicus, and Ae. japonicus.

\section{Materials and methods}

In summer 2017, surveillance of mosquito oviposition, using ovitraps, was performed in six federal states of AustriaTyrol, Carinthia, Vienna, Lower Austria, Styria, and Burgenland. For this, 70 sampling sites were used in Northern and Eastern Tyrol, 14 in Carinthia, 10 in Vienna, 10 in Lower Austria, 18 in Styria, and 7 in Burgenland. The sampling sites were at ground level in urban and rural gardens and public parks, as well as service areas along the highways in Tyrol. The sampling started at the beginning of June in Tyrol and Carinthia and in July in Vienna and Lower Austria and in August at the remaining sites in Styria and Burgenland. It ended at all sites at the end of October. The traps in Tyrol and Carinthia were sampled weekly, whereas the other sites were sampled once a month for a week. This study included the participation of citizen scientists at the sampling sites in Lower Austria, Styria, and Burgenland. The sampling sites in Vienna were the same as the sites for the routine mosquito surveillance for the city of Vienna, where adult female mosquitoes are collected in $\mathrm{CO}_{2}$-baited $\mathrm{BG}$ sentinel traps (Biogents, Regensburg, Germany) once per month over a 24-h period in the months May to September.

The method of using ovitraps has been utilized widely for surveillance of invasive Aedes species (Manica et al. 2017) (Fig. 1). We set up two 500-ml black conical cubs per site for 1 week, filled with approximately $400-\mathrm{ml}$ tap water, with wooden paddles $(2 \times 20 \mathrm{~cm}$ - rough plywood $)$ inserted into the water as a substrate for oviposition by the mosquito females. Since we partially relied on the help of citizen scientists, two information sheets were handed out with instructions on how to use the ovitraps. Participating citizen scientists sent used wooden paddles to the lab at the University of Veterinary Medicine in Vienna by mail. After collection, the wooden paddles were examined under a dissection microscope for Aedes eggs and the number of eggs present was counted. In Tyrol, the eggs were identified to species-level by morphology and validated by re-examination (MALDI-TOF) at the State Laboratory for South Tyrol Leifers. In the provinces Vienna, Lower Austria, Styria and Burgenland, the eggs underwent to DNA extraction and PCR. DNA was extracted from individual eggs using the Qiagen DNeasy Blood and Tissue kit (Qiagen, Germany). To each sample, $180 \mu \mathrm{l}$ buffer ATL, 
Fig. 1 Ovitrap sampling sites for Aedes mosquito eggs in six federal states of Austria (Tyrol, Carinthia, Vienna, Lower Austria, Styria, and Burgenland) during summer 2018

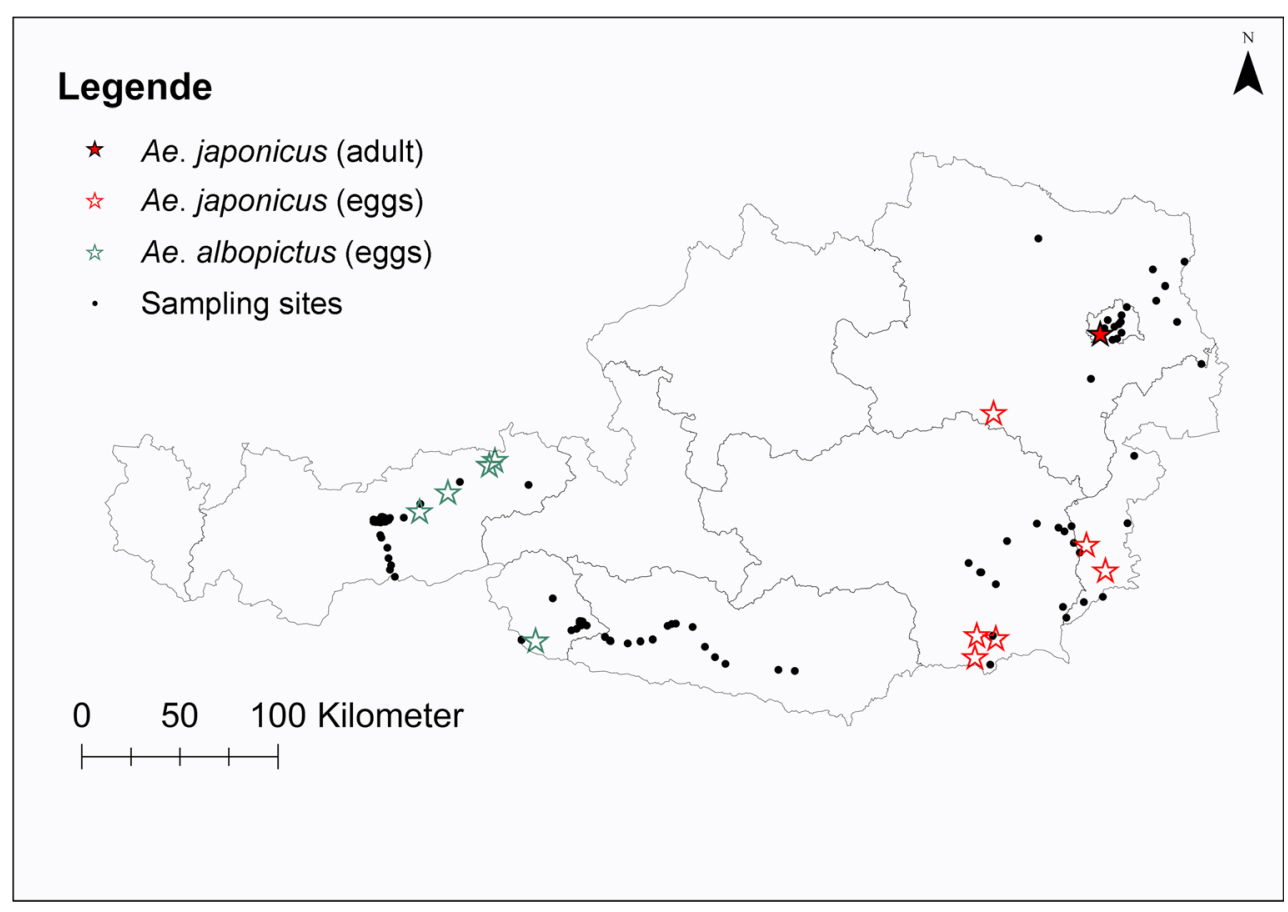

$20 \mu$ proteinase $\mathrm{K}$ and two ceramic beads (Precellys Ceramic Beads, Peqlab Biotechnologie $\mathrm{GmbH}$ ) were added and homogenized in a TissueLyser II (Qiagen, Germany). The samples were then incubated at $56{ }^{\circ} \mathrm{C}$ overnight and processed according to manufacturer's instructions. To identify mosquito species, a PCR was performed using the primers LCO1490 and HCO2198 as described in Folmer et al. (1994). Reaction products were commercially sequenced at LGC Genomics $\mathrm{GmbH}$, Germany, and resulting sequences compared for similarity to sequences available on the GenBank ${ }^{\circledR}$ database (http://www.ncbi.nlm.nih.gov/BLAST).

\section{Results and discussion}

During this project, eggs of alien mosquito species were found, but their presence varied by province and month. Eggs of Ae. albopictus were only detected in Tyrol along the Inn valley highway, while Ae. japonicus was found in Lower Austria, Styria and Burgenland (Table 1). In Vienna and Carinthia, all ovitraps were negative for Aedes eggs. However, Ae. japonicus was found for the first time during routine sampling of adult mosquitoes in Vienna in July 2017. In Lower Austria, one site was positive for eggs of Ae. japonicus in July and August 2017, in Styria, two sites were positive for Ae. japonicus eggs in August and one site in September (Fig. 2). Aedes japonicus was also identified in Burgenland, where two sites were positive in August. Aedes albopictus eggs were only detected in Tyrol, where four sites were positive in
August and three sites were positive in September. Most eggs were detected in Northern Tyrol at four different sites. Only one site in Eastern Tyrol was positive for Ae. albopictus eggs in August (Table 1). Aedes koreicus was not found at any of the examined sites.

During this study, 35 citizen scientists participated in Lower Austria, Styria, and Burgenland (Table 2). Participation remained high during the sampling months August to October 2017 (with 91.4\% in August and 82.9\% in both September and October), although the start of the study was delayed for July due to logistical and financial (delayed start of project funding) reasons. Therefore, only citizen scientists from Lower Austria were participating in July 2017. Drop out reasons for volunteers included holidays abroad, blown over ovitrap cups, loss of wooden paddle, or the sampling date was forgotten.

Eggs of the alien mosquito species Ae. albopictus and Ae. japonicus were found in four of the examined federal states of Austria during the late summer months of 2017, with Ae. albopictus detected in Tyrol only. The Asian tiger mosquito, which is native to South East Asia, is currently restricted mainly to Southern Europe, but due to ongoing climate change is expected to expand its range further northwards (Caminade et al. 2012; Medlock et al. 2015; Cunze et al. 2016a, b). It is established in Italy and has even reached its southernmost Mediterranean islands (Di Luca et al. 2017) and likely played a role in the Italian outbreak of Chikungunya virus in 2007 (Poletti et al. 2011; Carrieri et al. 2012). Aedes albopictus is now also found in Switzerland (Flacio et al. 2016) and Germany 
Table 1 Eggs of alien mosquito species collected in positive individual ovitraps in summer 2017 in the Austrian federal states Tyrol, Lower Austria, Styria, and Burgenland

\begin{tabular}{lllllr}
\hline Month & Calendar week & Province & Town & Species found & $\begin{array}{c}\text { Number of } \\
\text { eggs present }\end{array}$ \\
\hline July & 29 & Lower Austria & Kernhof & Aedes japonicus & 9 \\
August & 34 & Lower Austria & Kernhof & Aedes japonicus & 12 \\
August & 31 & Styria & Leibnitz & Aedes japonicus & 29 \\
August & 32 & Styria & St.Johann im Saggautal & Aedes japonicus & 33 \\
August & 35 & Styria & St. Andrä-Höch & Aedes japonicus & 52 \\
August & 35 & Burgenland & Rechnitz & Aedes japonicus & 12 \\
September & 37 & Burgenland & Sigleß & Aedes japonicus & 16 \\
August & 34 & Tyrol & Tassenbach & Aedes albopictus & 1 \\
August & 33 & Tyrol & Weer & Aedes albopictus & 25 \\
August & 34 & Tyrol & Weer & Aedes albopictus & 13 \\
September & 36 & Tyrol & Weer & Aedes albopictus & 7 \\
August & 35 & Tyrol & Münster & Aedes albopictus & 25 \\
September & 36 & Tyrol & Langkampfen & Aedes albopictus & 4 \\
August & 34 & Tyrol & Kufstein & Aedes albopictus & 47 \\
September & 36 & Tyrol & Kufstein & Aedes albopictus & 52 \\
\hline
\end{tabular}

(Becker et al. 2017), countries neighboring Austria. Most Ae. albopictus eggs in this study were found in Northern Tyrol, where the first eggs were documented in 2016 at one site along the main travel routes from Italy (Walder 2017). In 2016, no adult mosquitoes were caught at that particular oviposition site and a singular event was assumed, confirmed in 2017, when no further eggs were detected at the site. However, in contrast to previous years, in 2017, there was repeated evidence of oviposition at several sites with a high egg count in the Lower Inn Valley. Although this does not provided proof for the establishment of a self-sustaining population of the Asian tiger mosquito in Northern Tyrol, the distribution of the positive sites and the time of detection are indicative of

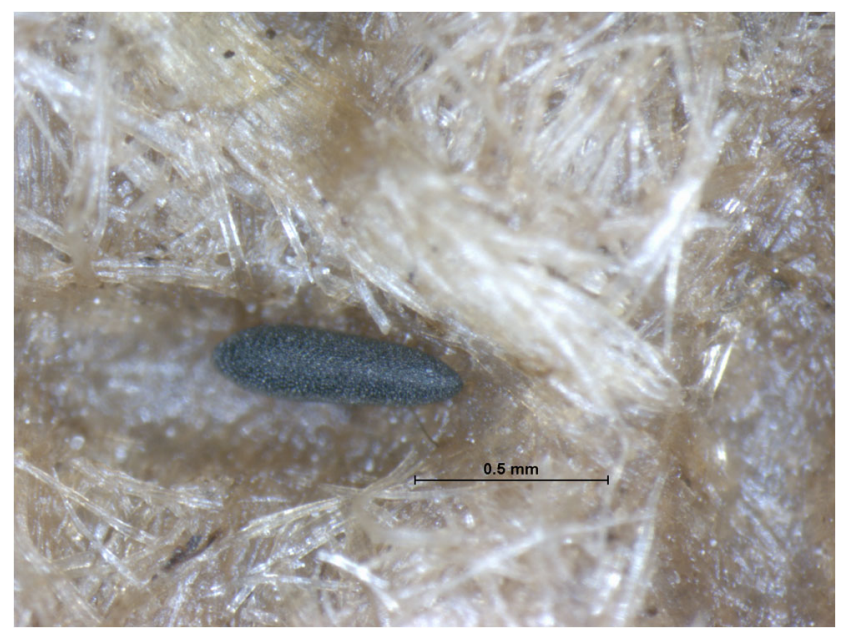

Fig. 2 Aedes japonicus egg on a wooden paddle from an ovitrap in Lower Austria continuous introduction and the local reproduction of these introduced individuals. In Eastern Tyrol, Ae. albopictus eggs were found for the first time and this shows that tiger mosquitoes were transported northward from Southern Tyrol and Trentino (Italy) and survived long enough to lay eggs.

In future years, it is likely that Ae. albopictus will disperse further along travel routes from the South and future surveillance will show if the species is able to establish a selfsustaining population.

Like Ae. albopictus, Ae.japonicus is expanding its range in Europe (Cunze et al. 2016a, b). During this study, eggs of this species were found in three Austrian states and adult individuals were caught in Vienna for the first time. This finding is not surprising, since Ae. japonicus has been spreading in Austria in recent years and has been present in Carinthia, Burgenland, Vorarlberg, and Tyrol (Zittra et al. 2017a; Seidel et al. 2016a, b). It has also been found in the neighboring countries of Germany (Kampen et al. 2016), Hungary (Seidel et al. 2016a, b), and Italy (Seidel et al. 2016a, b).

Table 2 Citizen scientist contribution in Lower Austria, Styria, and Burgenland

\begin{tabular}{lll}
\hline Month & $\begin{array}{l}\text { Participated } \\
\text { (out of a total of } 35 \\
\text { volunteers): } n(\%)\end{array}$ & $\begin{array}{l}\text { Number of positive } \\
\text { citizen scientist sites } \\
\text { (Ae. japonicus) }\end{array}$ \\
\hline July 2017 & $8(22.9 \%)$ & $1(12.5 \%)$ \\
August 2017 & $32(91.4 \%)$ & $5(15.6 \%)$ \\
September 2017 & $29(82.9 \%)$ & $1(3.4 \%)$ \\
October 2017 & $29(82.9 \%)$ & 0 \\
\hline
\end{tabular}




\section{Conclusion}

With this project, we demonstrated the benefits of citizen scientists for mosquito surveillance using ovitraps. The detection of Ae. albopictus eggs in Northern Tyrol is not yet a proof of the establishment of a self-sustaining population, although the distribution of the positive sites and the time of detection are indicative of the ongoing introduction of this species along main traffic routes from Italy, where this mosquito is well established. The risk of establishment of the Asian tiger mosquito in the Lower Inn Valley is therefore high and we recommend informing the general public about preventive measures to hinder and delay this development.

Acknowledgements Open access funding provided by University of Veterinary Medicine Vienna. We are grateful to all citizen scientists who devotedly supported this project.

Funding This project was funded in the scope of StartClim 2017 with financial support by the BMLFUW (Bundesministerium für Land- und Forstwirtschaft, Umwelt, und Wasserwirtschaft), BMWFW (Bundesministerium für Wissenschaft, Forschung, und Wirtschaft), the provinces Tyrol and Burgenland, and the city of Vienna.

\section{Compliance with ethical standards}

Conflict of interest The authors declare that they have no conflict of interest.

Open Access This article is distributed under the terms of the Creative Commons Attribution 4.0 International License (http:// creativecommons.org/licenses/by/4.0/), which permits unrestricted use, distribution, and reproduction in any medium, provided you give appropriate credit to the original author(s) and the source, provide a link to the Creative Commons license, and indicate if changes were made.

\section{References}

Baldacchino F, Bussola F, Arnoldi D, Marcantonio M, Montarsi F, Capelli G, Rosa R, Rizzoli A (2017) An integrated pest control strategy against the Asian tiger mosquito in northern Italy: a case study. Pest Manag Sci 73(1):87-93

Becker N, Schon S, Klein AM, Ferstl I, Kizgin A, Tannich E, Kuhn C, Pluskota B, Jost A (2017) First mass development of Aedes albopictus (Diptera: Culicidae)-its surveillance and control in Germany. Parasitol Res 116(3):847-858

Bonizzoni M, Gasperi G, Chen XG, James AA (2013) The invasive mosquito species Aedes albopictus: current knowledge and future perspectives. Trends Parasitol 29(9):460-468

Caminade C, Medlock JM, Ducheyne E, McIntyre KM, Leach S, Baylis M, Morse AP (2012) Suitability of European climate for the Asian tiger mosquito Aedes albopictus: recent trends and future scenarios. J R Soc Interface 9(75):2708-2717

Carrieri M, Angelini P, Venturelli C, Maccagnani B, Bellini R (2012) Aedes albopictus (Diptera: Culicidae) population size survey in the 2007 Chikungunya outbreak area in Italy. II: estimating epidemic thresholds. J Med Entomol 49(2):388-399

Cunze S, Koch LK, Kochmann J, Klimpel S (2016a) Aedes albopictus and Aedes japonicus - two invasive mosquito species with different temperature niches in Europe. Parasit Vectors 9. https://doi.org/10. 1186/s13071-016-1853-2

Cunze S, Kochmann J, Koch LK, Klimpel S (2016b) Aedes albopictus and its environmental limits in europe. PLoS One 11(9). https://doi. org/10.1371/journal.pone.0162116

Di Luca M, Toma L, Severini F, Boccolini D, D’Avola S, Todaro D, Stancanelli A, Antoci F, La Russa F, Casano S, Sotera SD, Carraffa E, Versteirt V, Schaffner F, Romi R, Torina A (2017) First record of the invasive mosquito species Aedes (Stegomyia) albopictus (Diptera: Culicidae) on the southernmost Mediterranean islands of Italy and Europe. Parasit Vectors 10. https://doi.org/10. 1186/s13071-017-2488-7

European Centre for Disease Prevention and Control (2012) Guidelines for the surveillance of invasive mosquitoes in Europe. Stockholm: ECDC. Stockholm, August 2012 ISBN 978-929193-378-5. https:// doi.org/10.2900/61134

Ferreira-de-Lima VH, Lima-Camara TN (2018) Natural vertical transmission of dengue virus in Aedes aegypti and Aedes albopictus: a systematic review. Parasit Vectors 11. https://doi.org/10.1186/s13071018-2643-9

Flacio E, L. Engeler L, Tonolla M, Muller P (2016) Spread and establishment of Aedes albopictus in southern Switzerland between 2003 and 2014: an analysis of oviposition data and weather conditions. Parasit Vectors 9. https://doi.org/10.1186/s13071-016-1577-3

Folmer O, Black M, Hoeh W, Lutz R, Vrijenhoek R (1994) DNA primers for amplification of mitochondrial cytochrome c oxidase subunit I from diverse metazoan invertebrates. Mol Mar Biol Biotechnol 3(5): 294-299

Goubert C, Henri H, Minard G, Moro CV, Mavingui P, Vieira C, Boulesteix M (2017) High-throughput sequencing of transposable element insertions suggests adaptive evolution of the invasive Asian tiger mosquito towards temperate environments. Mol Ecol 26(15): 3968-3981

Jordan RC, Sorensen AE, Ladeau S (2017) Citizen science as a tool for mosquito control. J Am Mosq Control Assoc 33(3):241-245

Kampen HC, Kuhlisch C, Frohlich A, Scheuch DE, Walther D (2016) Occurrence and spread of the invasive Asian bush mosquito Aedes japonicus japonicus (Diptera: Culicidae) in West and North Germany since detection in 2012 and 2013, respectively. PLoS One 11(12). https://doi.org/10.1371/journal.pone.0167948

Lebl K, Nichler EM, Walter M, Brugger K, Rubel F (2013) First record of the disease vector Anopheles hyrcanus in Austria. J Am Mosq Control Assoc 29:59-60

Manica MR, Rosa R, della Torre A, Caputo B (2017) From eggs to bites: do ovitrap data provide reliable estimates of Aedes albopictus biting females? Peerj 5:e2998. https://doi.org/10.7717/peerj.2998

Medlock JM, Hansford KM, Schaffner F, Versteirt V, Hendrickx G, Zeller $\mathrm{H}$, Van Bortel W (2012) A review of the invasive mosquitoes in Europe: ecology, public health risks, and control options. Vector Borne Zoonotic Dis 12(6):435-447

Medlock JM, Hansford KM, Versteirt V, Cull B, Kampen H, Fontenille D, Hendrickx G, Zeller H, Van Bortel W, Schaffner F (2015) An entomological review of invasive mosquitoes in Europe. Bull Entomol Res 105(6):637-663

Palmer JRB, Oltra A, Collantes F, Delgado JA, Lucientes J, Delacour S, Bengoa M, Eritja R, Bartumeus F (2017) Citizen science provides a reliable and scalable tool to track disease-carrying mosquitoes. Nat Commun 8(1):916. https://doi.org/10.1038/s41467-017-00914-9

Paupy C, Delatte H, Bagny L, Corbel V, Fontenille D (2009) Aedes albopictus, an arbovirus vector: from the darkness to the light. Microbes Inf 11(14-15):1177-1185

Poletti P, Messeri G, Ajellii M, Vallorani R, Rizzo C, Merler S (2011) Transmission potential of Chikungunya virus and control measures: the case of Italy. PLoS One 6(5). https://doi.org/10.1371/journal. pone. 0018860 
Rezza G (2012) Aedes albopictus and the reemergence of dengue. BMC Public Health 12. https://doi.org/10.1186/1471-2458-12-72

Schaffner F, Medlock JM, Van Bortel W (2013) Public health significance of invasive mosquitoes in Europe. Clin Microbiol Infect 19(8):685692

Seidel B, Duh D, Nowotny N, Allerberger F (2012) Erstnachweis der Stechmücken Aedes (Ochlerotatus) japonicus japonicus (Theobald, 1901) in Österreich und Slowenien in 2011 und für Aedes (Stegomyia) albopictus (Skuse, 1895)in Österreich 2012 (Diptera: Culicidae). Entomol.Z. 122:223-226

Seidel B, Hufnagl P, Indra A, Allerberger F (2013a) First record of Anopheles hyrcanus (Pallas, 1771) for Austria (Diptera: Culicidae). Entomol Z 125:39-41

Seidel B, Nowotny N, Duh D, Indra A,Hufnagl P, Allerberger F (2013b) First records of the thermophilic mosquito Culiseta longiareolata (Macquart 1838) in Austria, 2012 and in Slovenia, 2013. J Eur Mosquito Control Assoc 31, 17-20

Seidel B, Montarsi F, Huemer HP, Indra A, Capelli G, Allerberger F, Nowotny N (2016a) First record of the Asian bush mosquito, Aedes japonicus japonicus, in Italy: invasion from an established Austrian population. Parasit Vectors 9. https://doi.org/10.1186/ s13071-016-1566-6

Seidel B, Nowotny N, Bakonyi T, Allerberger F, Schaffner F (2016b) Spread of Aedes japonicus japonicus (Theobald, 1901) in Austria, 2011-2015, and first records of the subspecies for Hungary, 2012, and the principality of Liechtenstein, 2015. Parasit Vectors 9. https:// doi.org/10.1186/s13071-016-1645-8

Velo E, Kadriaj P, Mersini K, Shukullari A, Manxhari B, Simaku A, Hoxha A, Caputo B, Bolzoni L, Rosa R, Bino S, Reiter P, della Torre A (2016) Enhancement of Aedes albopictus collections by ovitrap and sticky adult trap. Parasit Vectors 9. https://doi.org/10. 1186/s13071-016-1501-x
Wagner S, Mathis A, Schonenberger AC, Becker S, Schmidt-Chanasit J, Silaghi C, Veronesi E (2018) Vector competence of field populations of the mosquito species Aedes japonicus japonicus and Culex pipiens from Switzerland for two West Nile virus strains. Med Vet Entomol 32(1):121-124

Walder G (2017) Monitoring of Aedes albopictus in the Tyrol. Annual report Außervillgraten 2017

Walder G, Simeoni J, Strasser H, Zelger R (2013) EU-Interreg IV: project VEIT final report, Innsbruck, p 2013

Walter D, Kampen H (2017) The citizen science project 'Mueckenatlas' helps monitor the distribution and spread of invasive mosquito species in Germany. J Med Entomol 54(6):1790-1794

Zittra C, Waringer J, Werblow A, Melaun C, Fuehrer HP (2014) Reconfirmation of Culiseta (Allotheobaldia) longiareolata (Macquart,1838)(Diptera: Culicidae) in Austria. The first sequence confirmed findings in North-Eastern Austria. Acta ZooBot Austria 150/151:17-24

Zittra C, Joachim A, Fuehrer HP (2015) Mosquitoes and Dirofilaria in Austria - a review of the current situation of neobiotic Culicidae and Dirofilariae. Tieraerztl Umsch 70(4):126-131

Zittra C, Lechthaler W, Mohrig W, Car M (2017a) Diptera: Culicidae. In Moog, O. \& A. Hartmann (Eds.): Fauna Aquatica Austriaca, 3. Edition 2017. BMLFUW, Wien

Zittra C, Obwaller AG, Wimmer V, Berer D, Eigner B, Fuehrer HP (2017b) First record of Orthopodomyia pulcripalpis (Rondani, 1872) (Diptera: Culicidae) in Austria. Parasitol Res 116(6):17811783

Publisher's note Springer Nature remains neutral with regard to jurisdictional claims in published maps and institutional affiliations. 